\title{
A STUDY OF HISTOMORPHOLOGY OF OVARIAN NEOPLASMS
}

\author{
HAQUE $\mathrm{E}^{1}$, HUQ $\mathrm{N}^{2}$, YUSUF $\mathrm{A}^{3}$, KHANAM $\mathrm{S}^{4}$, RAHMAN KM ${ }^{5}$
}

\begin{abstract}
:
Background: Ovarian malignancy is one of the most common causes of cancer deaths in females in Bangladesh. Due to poor early symptoms and lack of screening protocol, it is detected later in the clinical course of the disease. It is also one of the most treatable tumors because majorities are sensitive to chemo-radiation. An accurate histology is often a critical factor in achieving optimum treatment response.

Objective: To study the frequency and histological patterns of neoplastic ovarian lesions.

Methodology: A retrospective cross sectional study was done. We analyzed the data compiled from ovarian lesions biopsied and reported in a private diagnostic center from January 2008 to December 2015.

Results: Out of 231 ovarian specimens only 66 were neoplastic lesions, while the rest were nonneoplastic cysts. The age range was 9 to 65 years with a mean of $36.58 \pm 10.45$. 73 percent (48) were benign, 6.01 percent (4) were borderline and 21.21 percent (14) were malignant. Surface epithelial tumors were the most common ovarian neoplasm ( $n=48 ; 72.73 \%)$ followed by germ cell tumor ( $n=14 ; 21.21 \%)$ and sex cord stromal tumor ( $n=4 ; 6.01 \%)$. Serous cystadenoma was the commonest benign tumor (23) followed by dermoid cyst (11), and mucinous cystadenoma (10). Only 4 borderline malignant tumors were found; 03 of which were mucinous and 01 serous. The number of malignant tumor was 18. Malignant mucinous neoplasm was the commonest, in both invasive carcinoma (05) and borderline group (03).
\end{abstract}

Conclusion: Benign ovarian neoplasm was more common than malignant ones. Surface epithelial tumor was the frequent group followed by germ cell tumor. Serous cystadenoma was most common among benign tumors whereas mucinous cystadenocarcinoma was the commonest malignant tumor.

Keywords: Ovarian tumor, Surface epithelial tumor, Serous cystadenoma, Mucinous cystadenocarcinoma.

J Dhaka Med Coll. 2018; 27(1) : 25-28

\section{Introduction:}

Ovary is a common site for both neoplastic and non-neoplastic lesions. The spectrum of ovarian lesions is wide, from harmless simple cystic lesions to fatal aggressive malignant ones. Incidence of ovarian cancers is increasing and it is an important cause of cancer deaths in women in our country. The survival rate is low due to absence of effective tumor markers, screening protocol and the disease seldom produces symptoms before getting complicated or huge size ${ }^{1,2}$. Early diagnosis is important for better management of the patients. Large proportions of cystic masses are physiological like follicular cysts, corpus luteal cysts and usually they do not need any surgical intervention. It is an organ related to progeny. Unnecessary surgical intervention is to be avoided especially in case of prepubertal or young nulliparous lady. Bimanual examination, pelvic ultrasound, and tumor markers are available tools for pre-operative diagnosis and are not sufficient to differentiate neoplastic and non-neoplastic cystic lesions. It is also difficult to differentiate between benign and malignant tumors unless there is development of

1. Dr. Enamul Haque, Junior Consultant (Gynae), General Hospital Munshiganj

2. Dr. Naila Huq, Associate professor (Pathology), Department of Neuropathology, National Institute of Neurosciences \& Hospital, Dhaka.

3. Dr. Abdullah Yusuf, Assistant professor, Microbiology, National Institute of Neurosciences \& Hospital, Dhaka

4. Dr. Shahana Khanam, Associate Professor, Deprtment of Microbiology, MH Shamarita Medical College, Dhaka

5. Dr. Kazi Monisur Rahman, Assistant Professor, Departent of Gastroenterology, BSMMU, Dhaka

Correspondence :Dr. Enamul Haque, Junior consultant (Gynae), General Hospital Munshiganj. Email: doctorenamk 43@gmail.com 
complications. Histopathological examination of the tissue is considered as the gold standard for definitive diagnosis of these lesions ${ }^{3}$. This study was carried out to see the frequency and the histomorphological patterns of neoplastic tumors.

\section{Methodology:}

This retrospective analytical study included all cases of ovarian specimen collected and reported in a private laboratory of Dhaka city from January 2008 to December 2015. A total of 231 cases were included in the study which was subdivided into two groups: Group I (Nonneoplastic lesions) and group 2 (Neoplastic lesions). All the samples were fixed in 10\% formalin and stained by routine Hematoxyline $\&$ Eosin stain. Histological diagnosis was based on the standard reference books of histopathology ${ }^{3,4}$. The neoplasms were divided into surface epithelial, germ cell and sex cord stromal tumors. Non neoplastic lesions were not further analyzed in this study.

\section{Result:}

During the study period 231 specimens of ovarian lesions were retrieved from the computerized data base. Out of those cases 165 were non neoplastic ovarian lesions and while 66 were neoplastic lesions.

Mean age of the patients was $36.58 \pm 10.45$ years ranging from 9 to 65 years.

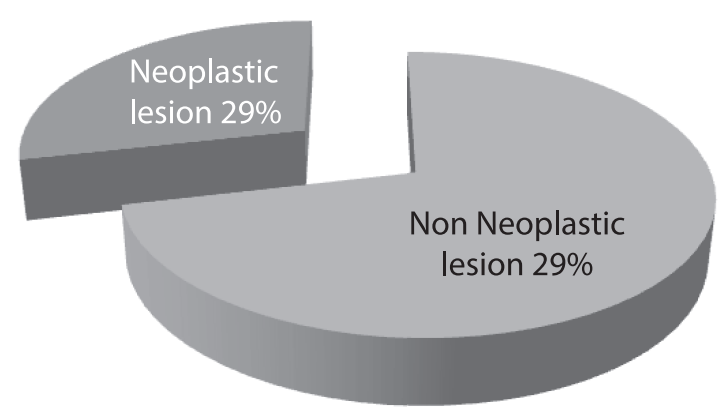

Fig.-1: Distribution of Types of Ovarian Lesion $(n=231)$

Among the neoplastic ovarian lesions, 73 percent (48) were benign, 6.01 percent (4) were borderline and 21.21 percent (14) were malignant. Among all ovarian neoplasm which included both benign and malignant groups, surface epithelial tumors were the most common ( $\mathrm{n}=48 ; 72.73 \%$ ) followed by germ cell tumor $(\mathrm{n}=14 ; 21.21 \%)$ and sex cord stromal tumor $(\mathrm{n}=4 ; 6.01 \%)$. We did not found any metastatic tumor.

Table-I

Distribution of Types of benign ovarian tumors $(n=48)$

\begin{tabular}{lcc}
\hline Benign tumors & Frequency & $\begin{array}{c}\text { Valid } \\
\text { Percent }\end{array}$ \\
\hline Serous cystadenofibroma & 2 & 4.2 \\
Mucinous cystadenofibroma & 1 & 2.1 \\
Bilateral ovarian fibroma & 1 & 2.1 \\
Serous cystadenoma & 23 & 47.9 \\
Mucinous cystadenoma & 10 & 20.8 \\
Demoid Cyst & 11 & 22.9 \\
\hline Total & 48 & 100.0 \\
\hline
\end{tabular}

Out of 48 benign tumors 36 (75\%) were surface epithelial tumor, $11(22.92 \%)$ germ cell tumors and only 01 case was of sex cord stromal tumor. Serous cystadenoma was the commonest benign tumor (23) followed by dermoid cyst (11), and mucinous cystadenoma (10).

\section{Table-II}

Distribution of Types of malignant ovarian tumors $(n=18)$

\begin{tabular}{lcc}
\hline Malignant tumor & Frequency & $\begin{array}{c}\text { Valid } \\
\text { Percent }\end{array}$ \\
\hline Dysgerminoma & 2 & 11.1 \\
Granulosa cell tumor & 2 & 11.1 \\
Juvenile granulosa cell tumor & 1 & 5.5 \\
Endometroid carcinoma & 1 & 5.5 \\
Immature teratoma & 1 & 5.5 \\
Adenocarcinoma,poorly & 1 & 5.5 \\
differentiated & & \\
Serous cystadenocarcinoma & 1 & 5.5 \\
Mucinous cystadenocarcinoma5 & 27.8 \\
Borderline serous neoplasm & 1 & 5.5 \\
Borderline mucinous neoplasm3 & 16.7 \\
\hline \multicolumn{2}{l}{ Total } & 18 \\
\hline
\end{tabular}


In this study, the number of malignant tumor was 18 . Only 4 borderline malignant tumor were found; 03 of which were mucinous and 01 serous. The number of malignant surface epithelial tumor was 07, germ cell tumor 03 and sex cord stromal tumor 03. Malignant mucinous neoplasm was the commonest, in both invasive carcinoma (05) and borderline tumor (03). Granulosa cell tumors were found in both juvenile age and post menopausal age group.

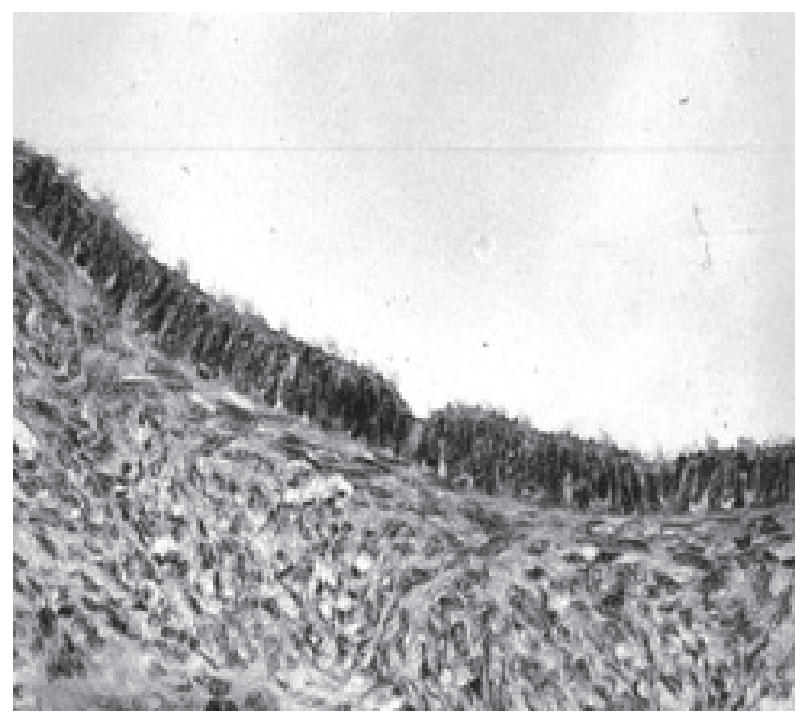

Fig.-2: Photomicrograph of serous cystadenoma

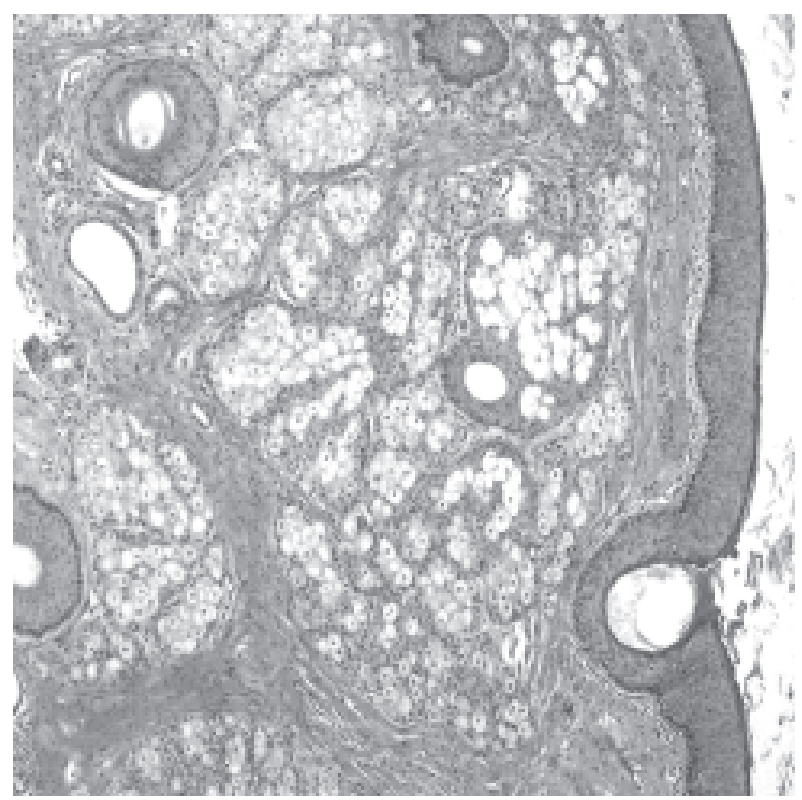

Fig.-3: Photomicrograph of Dermoid cyst

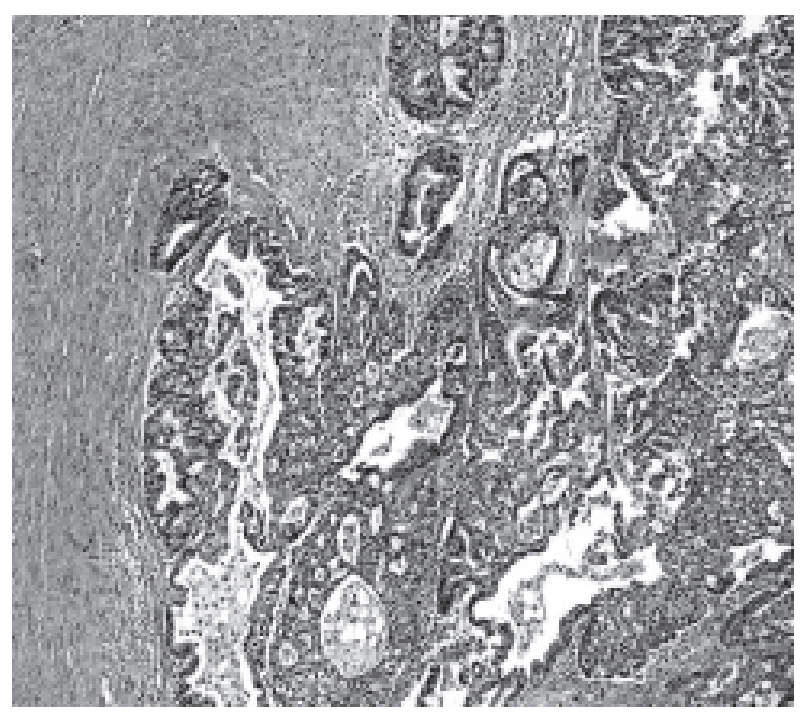

Fig.-4: Photomicrograph of Mucinous cystad enocarcinoma

\section{Discussion:}

Age range of our patients was from 9 years to 65 years and the mean age was $36.58 \pm 10.45$ years. Mean age of our study was similar to other study ${ }^{1,5,6,7}$. In the present study we found a higher percentage of non-neoplastic lesions. The percentage of non-neoplastic lesions was $71.4 \%$ and neoplastic lesions $28.6 \%$. This findings is similar to a study done in Kerala, India ${ }^{8}$. They found about $60 \%$ non-neoplastic lesions and $40 \%$ neoplastic lesion. But another study in Saudi Arabia shows a higher percentage of neoplastic lesions. They found $61.8 \%$ ovarian neoplasm and only $38.2 \%$ nonneoplastic lesions which is much different than our study ${ }^{9}$. This variation may result from difference in geographical and environmental factors.

Among different subtypes of ovarian tumors, surface epithelial tumor was the most common category followed by germ cell tumor and sex cord stromal tumor. This finding concurs with data from other study $2,5,6,10,11,12$. This study reveals $73 \%$ of the ovarian neoplasms were benign while $21.21 \%$ malignant variety. The percentage of borderline tumor was very low only $6.01 \%$. Many other study from Nepal, Pakistan, India and Saudi Arabia also showed similar type of findings $1,5,6,8,13$.

Out of 48 benign ovarian neoplasm the most common was surface epithelial tumor and the 
number was 37 including both serous and mucinous tumor. Germ cell tumor was the second most common group and it comprises of mature cystic teratoma $(n=11)$. There was one case of bilateral ovarian fibroma. Most of the study showed surface epithelial tumors as the commonest benign tumor $1,2,5,6,8,10,11,12$.

04 borderline neoplasms were found in the current study in which 3 were mucinous borderline neoplasm and only 1 serous borderline neoplasm. Mucinous neoplasm was also the most common type among malignant group .This findings is dissimilar with all other study reported by authors of different countries of Asia like India, Pakistan, Nepal, and Saudi Arabia 1,5,9,11,12,13. But Hashmi AA et al. reported mucinous cystadenocarcinoma as the commonest malignant tumor in a study done in Pakistan ${ }^{7}$. These differences may result from difference in the study period, sample size, variation in diagnostic criteria of different pathologists ${ }^{9}$. The current study was done with a small sample size. Further multicenter study with larger sample sizes is required for better understanding.

\section{Conclusion:}

In our study benign tumor was more common than malignant tumors. Surface epithelial tumor was the most common group. Among the benign tumor serous cystadenoma was the commonest type whereas mucinous cystadenocarcinoma was the commonest malignant tumor.

\section{References}

1. Pradhan A, Sinha A.K, Upreti D. Histopathological patterns of ovarian tumor in BPKIHS. May -August 2012: vol.10 (No 2)87-97.

2. Tejeswini V, Reddy ES,Premalatha P et al .Study of morphological patterns of ovarian neoplasm.IOSR Journal of Dental and Medical Sciences (IOSR- JDMS)
e-ISSN: 2279-0861.Vol 10, Issue 6 (Sep.-Oct. 2013), PP 11-16.

3. Rosenblum MK. Female reproductive system. In: Rosai J. Ed. Rosai and Ackerman's Surgical Pathology $10^{\text {th }}$ Ed. St Louis, Mo. Elsevier.2010.Vol-2, PP 15531606.

4. Ellenson LH and Pirog EC. The female Genital Tract in: Robbins and Cotran pathologic Basis of Disease. $8^{\text {th }}$ Ed. Elsevier.2012, PP 1039-1052.

5. Khan M A, Shah HU, Qayym A. Histopathological pattern of ovarian tumors in various age groups. J Post grad Med Inst 2017; 31(3);251-5

6. Kancheria J, KalahastiR, ChandraShekhar KPA et al. Histomorphological Study of Ovarian Tumors : An Institutional Experience of 2 Years. International Journal of Scientific Study. 2017 June; Vol 5; issue3: 232-235.

7. Hashmi AA, Hussain ZF, Bhagwani AR et al. Clinicopathologic features of ovarian neoplasms with emphasis on borderline ovarian tumors: an institutional perspective.BMC Res Notes(2016)9:205

8. Wills V, Mathew R. A study on clinic-histopathological patterns of ovarian tumors. International Journal of Reproduction, Contraception, Obstetric and Gynecology.2016 Aug ; 5(8): 2666-2671

9. Abdullah LS, Bondagji NS. Histopathological pattern of ovarian neoplasms and their age distributions in the western region of Saudi Arabia. Saudi Med J 2012; Vol. 33(1):61-65

10. Ghosh A, Ghartimagar D, Thapa S et al. Ovarian Tumors-Pattern of Histomorphological Types-A 10 Years Study in a Tertiary Referral Centre and Review of Literature. Kathmandu Univ Med J 2016; 54(2):153-8

11. Modi D, Rathord GB, Delwadia KN. Histopathological pattern of neoplastic ovarian lesions.JAIM,2016; 3(1): 51-57.

12. Mondal SK, Banyopadhyay R, Nag Dr et al. Histological pattern, bilaterality and clinical evaluation of 957 ovarian neoplasms: A 10 year study in a tertiary hospital of eastern India. Journal of Cancer Research and Therapeutics- 2011 Oct.-Dec. Vol 7 issue 4: 433-437.

13. Ahmad Z, KayaniN, Sheema $\mathrm{H}$ et al. Histological patterns of ovarian neoplasm 